\title{
PENGALAMAN PERAWAT DALAM MENERAPKAN MANAJEMEN PENGENDALIAN INFEKSI DI RSUP H. ADAM MALIK MEDAN
}

\author{
Helfrida Situmorang \\ Program Studi Diploma III Keperawatan \\ Akademi Keperawatan Indah Medan, Indonesia \\ E-mail: situmoranghelfrida@gmail.com
}

Diterima: Maret 2017, diterbitkan: April 2018

\begin{abstract}
Abstrak
Pencegahan dan Pengendalian Infeksi (PPI) rumah sakit adalah kegiatan yang meliputi perencanaan, pelaksanaan dan pengawasan serta pembinaan dalam upaya menurunkan angka kejadian Infeksi Rumah Sakit (IRS) pada pasien atau petugas rumah sakit dan mengamankan lingkungan rumah sakit dari risiko transmisi infeksi yang dilaksanakan melalui manajemen risiko, tata laksana klinik yang baik dan pelaksanaan Kesehatan dan Keselamatan Kerja Rumah Sakit. Tujuan penelitian: mengeksplorasi pengalaman perawat dalam menerapkan manajemen pengendalian infeksi di RSUP H. Adam Malik Medan. Metode: Jenis penelitian ini merupakan studi kualitatif dengan desain fenomenologi deskriptif. Partisipan dalam penelitian ini adalah IPCLN (Infection Prevention Control Link Nurse) yaitu perawat penghubung pengendali infeksi, ditentukan dengan teknik Purposive Sampling. Pengumpulan data menggunakan metode wawancara secara mendalam terhadap 12 perawat IPCLN yang terdiri dari IPCLN yang bertugas di ruang rawat inap yang berisiko terjadi infeksi seperti ruang Neurologi (RA 4), RB 1 Obgyn, RA 2, CVCU, RB 4 Anak, R. Inap Kardio Vaskuler Lantai 4, RB 3, VIP B, RB 2 A, R. Inap Kardio Vaskuler Lantai 3, RA 3 THT, ICU Anak, di RSUP. H. Adam Malik Medan. Analisis data dilakukan setelah proses pengumpulan data pada bulan Juli 2016 dengan menggunakan tehnik analisis Colaizzi. Hasil: Hasil penelitian ini menemukan dua tema yaitu melakukan pengawasan yang ketat dan mendapatkan hambatan dalam melaksanakan pengendalian infeksi. Kesimpulan: Pengawasan terkait pengendalian infeksi sudah dilaksanakan dengan baik setiap hari dan setiap ada pasien baru. Hambatan yang didapat seperti beberapa petugas yang kurang patuh untuk menggunakan APD (Alat Pelindung Diri) dan melaksanakan cuci tangan.
\end{abstract}

Kata kunci: Pengendalian infeksi, manajemen, perawat

\section{NURSE'S EXPERIENCE IN APPLYING INFECTION CONTROL MANAGEMENT AT H. ADAM MALIK HOSPITAL OF MEDAN \\ Abstract}

Infection Prevention and Control at hospitals are activities that include planning, implementation and supervision as well as development in order to reduce the incidence of Hospital-acquired infection in patients or hospital personnel and to secure hospital environment from the risk of transmission of infection. It is carried out through management risk, good clinical management and implementation of Hospital Occupational Health and Safety. Objective: To explore the experience of nurses in implementing infection control management at H. Adam Malik Hospital of Medan. Methods: This research is qualitative with descriptive phenomenological design. Participants in this study were the Infection Prevention Control Link Nurses (IPCLNS), whom were taken using purposive sampling technique. Data were collected using in-depth interviews to 12 IPCLNs consisting of IPCLNs who served in the inpatient unit facing the risk of infection such as Neurology room (RA 4), RB 1 Obgyn, RA 2, CVCU, RB 4 for children, Cardio vascular Inpatient room 4th Floor, RB 3, VIP B, RB 2 A, Cardio vascular Inpatient room 3rd Floor, RA 3 ENT, ICU for Children at H. Adam Malik Hospital of Medan. Data were analyzed after the data were collected in July 2016 using the Colaizzi's method of data analysis. Results: The results of this study found two themes, namely strict supervision and obstacles in controlling infection. Conclusion: Supervision related to 
infection control has been carried out well every day and when a new patient is admitted. Obstacles include some officers who are less obedient to use PPE (Personal Protective Equipment) and to wash hand.

Keywords: Infection control, management, nurses

\section{PENDAHULUAN}

Proses manajemen adalah rangkaian kegiatan input, proses, dan output yang dibagi dalam empat tahap yaitu perencanaan, pengorganisasian, pengarahan dan pengawasan yang merupakan siklus yang berkaitan satu sama lain (Huber, 2010). Pencegahan dan Pengendalian Infeksi Rumah Sakit (PPIRS) adalah kegiatan yang meliputi perencanaan, pelaksanaan dan pengawasan serta pembinaan dalam upaya menurunkan angka kejadian Infeksi Rumah Sakit (IRS) pada pasien atau petugas rumah sakit dan mengamankan lingkungan rumah sakit dari resiko transmisi infeksi yang dilaksanakan melalui manajemen resiko, tata laksana klinik yang baik dan pelaksanaan Kesehatan dan Keselamatan Kerja RS (RSUD Kota Yogyakarta, 2015. Program pencegahan dan pengendalian infeksi bertujuan untuk melindungi pasien, petugas kesehatan, pengunjung dan lain-lain di dalam lingkungan rumah sakit serta penghematan biaya dan meningkatkan kualitas pelayanan rumah sakit dan fasilitas kesehatan lainnya dan yang paling penting adalah menurunkan angka kejadian infeksi nosokomial (Scheckler et al., 1998).

Creswell (1998) menjelaskan fenomenologi adalah maknanya bagi individu dihubungkan dengan prinsip-prinsip filosofis fenomenologi dan diakhiri dengan esensi dari makna. Berdasarkan hasil laporan dari unit Pencegahan Pengendalian Infeksi (PPI) di RSUP H. Adam Malik Medan penerapan manajemen pencegahan pengendalian infeksi sudah dilaksanakan sejak tahun 2006. IPCLN (Infection Prevention Control Link Nurse) sudah membuat perencanaan berupa jadwal pengarahan dan jadwal pengawasan yang sudah dilaksanakan setiap hari. Untuk pengorganisasian masih berkoordinasi dengan unit PPI dimana IPCLN bagian dari unit PPI sehingga IPCLN melaksanakan tugas sesuai arahan dari unit PPI. Pengarahan yang dilakukan IPCLN berupa penyuluhan kesehatan seperti cara mencuci tangan, pemakaian APD, etika batuk dan lain-lain dilaksanakan setiap serah terima baik terhadap perawat, pasien dan keluarga pasien serta pasien baru namun belum optimal. Pengawasan dilakukan IPCLN setiap hari di ruangan misalnya dalam melaksanakan tindakan keperawatan diperhatikan bagaimana mencuci tangan yang benar, momen yang tepat, penggunaan APD, pembuangan limbah, penggunaan peralatan yang steril dan membuat laporan surveilans. Namun masih dijumpai perawat salah mencuci tangan, momen yang tidak tepat dan tidak memperhatikan SOP (Standar Operasional Prosedur), IPCLN hanya memberi teguran tidak ada punishment dan reward sehingga prilaku perawat tidak berubah. Hal ini seiring dengan penelitian Ernawati, Tri R, \& Wiyanto (2014). yang melaporkan bahwa kepatuhan hand hygiene perawat ruang rawat inap rumah sakit masih rendah (35\%), kepatuhan tertinggi ditemukan sesudah kontak dengan cairan tubuh pasien sedangkan kepatuhan terendah bahkan nol pada momen sebelum kontak dengan pasien.

\section{METODE PENELITIAN}

Jenis penelitian ini merupakan studi kualitatif dengan Desain fenomenologi deskriptif dipilih agar peneliti dapat mengeksplorasi lebih mendalam tentang pengalaman perawat dalam menerapkan 
manajemen pengendalian infeksi di RSUP H. Adam Malik Medan.

Penelitian dilakukan di ruangan rawat inap yang beresiko terjadi infeksi seperti ruang Neurologi (RA4), RB 1 Obgyn, RA2, CVCU, RB 4 Anak, R. Inap Kardio Vaskuler Lantai 4, RB 3, VIP B, RB 2 A, R. Inap Kardio Vaskuler Lantai 3, RA 3 THT, ICU Anak, di RSUP. H. Adam Malik Medan. Proses pengumpulan data dilakukan dari bulan Juli 2016, dan analisis data dilakukan di bulan Juli - September 2016. Jumlah partisipan 12 orang: Partisipan dalam penelitian ini ditentukan dengan teknik purposive sampling yaitu partisipan yang dipilih atau yang diteliti diyakini berkompeten dan mau memberikan informasi terkait dengan manajemen pengendalian infeksi di ruangan tempat partisipan bertugas.

Pengumpulan data pada penelitian ini menggunakan metode wawancara secara mendalam dengan alat voice recorder dan berdasarkan panduan wawancara dengan pertanyaan terbuka dengan menggunakan catatan lapangan. Pedoman atau panduan wawancara dibuat berdasarkan landasan teori yang relevan dengan masalah yang digali dalam penelitian berdasarkan standar kewaspadaan (World Health Organization, Regional Office for South-East Asia and Regional Office for Western Pacific, 2004). Panduan wawancara dibuat oleh peneliti sendiri dan telah dilakukan uji validitas kepada 3 orang expert yang bertugas di RSUP $\mathrm{H}$. Adam Malik Medan. Peneliti melakukan wawancara terhadap partisipan 1-2 kali di ruangan yang telah disepakati antara peneliti dan partisipan seperti ruangan kepala ruangan, ruangan obat dan ruangan perawat tempat partisipan bertugas. Wawancara dilakukan dengan durasi 50-65 menit dan dilakukan sendiri oleh peneliti. Kemudian membuat transkrip wawancara dan analisis data pada penelitian ini dilakukan dengan menggunakan pendekatan dari Colaizzi, karena metode ini memberikan langkahlangkah yang sederhana, jelas, dan rinci dengan langkah-langkah sebagai berikut: 1) Membuat transkrip, peneliti memberikan nomor untuk setiap baris hasil transkrip; 2) membaca berulang kali transkrip data yang ada sehingga peneliti dapat menemukan pernyataan yang signifikan dan memberikan garis bawah pada pernyataan- pernyataan penting partisipan; 3) menentukan kategori, beberapa pernyataan yang mempunyai makna yang sama digabungkan menjadi satu kategori; 4) Menentukan subtema atau tema, Kategori yang sejenis digabungkan menjadi suatu subtema atau tema baru yang potensial; 5) Mengintegrasikan tema menjadi deskripsi lengkap dari fenomena yang diteliti; 6) Merumuskan deskripsi secara lengkap dari fenomena yang diteliti sebagai pernyataan yang jelas; 7) Menanyakan kembali partisipan tentang hasil temuan sebagai langkah validasi akhir untuk memastikan bahwa hasil temuan penelitian merupakan pengalaman partisipan yang sesungguhnya dan disetujui oleh partisipan tersebut (Colaizzi, 1978). Dalam melakukan analisis data, peneliti menggunakan bantuan software weft-QDA untuk memudahkan dalam pengorganisasian data.

Guba \& Lincoln (1994) mengemukakan bahwa tingkat keabsahan data hasil penelitian dapat dipercaya dengan memvalidasi data menurut beberapa kriteria, yaitu credibility, transferability, dependability, confirmability dan authenticity. Pada penelitian ini, prosedur pengumpulan data dimulai dari lulus uji etik (ethical clearence) dan izin penelitian dari Fakultas Keperawatan Universitas Sumatera Utara (F.Kep-USU). Surat tersebut diserahkan kepada bagian pendidikan dan pelatihan RSUP H. Adam Malik Medan. Setelah mendapatkan izin, selanjutnya peneliti mencari partisipan yang sesuai dengan kriteria yang telah ditentukan. 


\section{HASIL PENELITIAN}

Karakteristik demografi partisipan rawat inap, lama bekerja di RSUP H. Adam meliputi partisipan seluruhnya berjenis Malik Medan mayoritas di atas 19 tahun, dan kelamin perempuan 12 orang, usia partisipan semua partisipan sudah mengikuti pelatihan mayoritas diatas 35 tahun, pendidikan terkait pengendalian infeksi.

terbanyak S1, unit kerja mayoritas di ruang

Tabel 1. Karakteristik Demografi Partisipan

\begin{tabular}{ccccccc}
\hline Partisipan & $\begin{array}{c}\text { Jenis } \\
\text { Kelamin }\end{array}$ & Usia & Pendidikan & Unit kerja & $\begin{array}{c}\text { Lama } \\
\text { kerja }\end{array}$ & $\begin{array}{c}\text { Pelatihan } \\
\text { PPI }\end{array}$ \\
\hline 11 & $\operatorname{Pr}$ & 35 & S1 & RA 4 & 13 & 2014 \\
12 & $\operatorname{Pr}$ & 43 & D IV & RB 1 & 19 & 2015 \\
33 & $\operatorname{Pr}$ & 41 & S1 & RA 2 & 19 & 2015 \\
44 & $\operatorname{Pr}$ & 37 & S1 & CVCU & 14 & 2011 \\
55 & $\operatorname{Pr}$ & 39 & S1 & RB 4 & 19 & 2015 \\
66 & $\operatorname{Pr}$ & 27 & D3 & RIK Lt. 4 & 6 & 2013 \\
77 & $\operatorname{Pr}$ & 32 & S1 & RB 3 & 10 & 2015 \\
88 & $\operatorname{Pr}$ & 51 & D3 & VIP B & 25 & 2014 \\
99 & $\operatorname{Pr}$ & 44 & S1 & RB 2A & 20 & 2016 \\
110 & $\operatorname{Pr}$ & 38 & D3 & RIK Lt. 3 & 6 & 2015 \\
111 & $\operatorname{Pr}$ & 34 & S1 & RA 3 & 19 & 2015 \\
112 & $\operatorname{Pr}$ & 48 & D3 & ICU Anak & 22 & 2016 \\
\hline
\end{tabular}

\section{Sumber : Data Primer}

Berdasarkan hasil analisis terhadap hasil wawacara diperoleh dua tema yaitu: 1) Melakukan pengawasan yang ketat; 2) mendapatkan hambatan dalam melaksanakan pengendalian infeksi.

Berikut pengawasan pengendalian infeksi yang terlihat dalam sub tema yaitu: 1) Pengawasan terhadap pasien; 2) pengawasan terhadap petugas kesehatan; 3) pengawasan terhadap lingkungan; 4) pengawasan terhadap masalah yang ditemukan; 5) membuat laporan. Masingmasing sub tema dijelaskan sebagai berikut:

\section{Pengawasan terhadap pasien}

\section{a. Peralatan yang terpasang di tubuh pasien}

Semua partisipan mengungkapkan banyak hal yang diawasi IPCLN terkait pengendalian infeksi antara lain pasien yang terpasang infus, terpasang kateter, dilihat apakah ada tanda-tanda infeksi, tanggal pemasangan serta linen yang kotor. Seperti diungkapkan partisipan berikut ini:

"Yang sudah saya awasi yang pertama, pasien-pasien yang menggunakan infus, kateter, sudah lewat tanggal apa tidak, ada gak tanda-tanda plebitis, untuk kateter 
nya saya perhatikan sudah berapa lama ini pemasangannya sudah ada kristal, bagaimana jernih gak urinennya seperti itu, linennya juga seperti itu" [ P1, L 268-272]

\section{Pengawasan terhadap petugas kesehatan}

a. Kepatuhan petugas melaksanakan SOP

Semua partisipan mengungkapkan IPCLN juga mengawasi petugas kesehatan dalam pelaksanaan pengendalian infeksi sesuai SOP. Seperti diungkapkan partisipan berikut ini:

"Sepanjang ini dengan pemantauan aja, jadi pada saat jam dinas saya ya semua kita lihat, sambil bekerja kita pantau, sambil kita ingatkan cuci tangan gak itu dokternya" [ P4, L 251-252]

\section{Pengawasan terhadap lingkungan \\ a. Kebersihan ruangan}

Semua partisipan mengungkapkan IPCLN juga mengawasi kebersihan ruangan, kepatuhan pembuangan limbah, kepatuhan membersihkan alat-alat yang sudah dipakai pasien Seperti diungkapkan partisipan berikut ini:

"Masalah kebersihan ruangan, kepatuhan mencuci tangan, kepatuhan pembuangan limbah, kepatuhan membersihkan alat-alat yang sudah dipakai pasien" [ P6, L 285-286]

\section{Pengawasan terhadap masalah yang ditemukan}

a. Pengawasan terhadap kejadian infeksi

Sebagian partisipan mengungkapkan mengawasi kejadian infeksi antara lain plebitis, ISK. Seperti diungkapkan partisipan berikut ini:

"Plebitis lah, ISK karena pemasangan kateter, itu aja” [ P3, L 103]

\section{b. Perilaku buruk dari keluarga pasien}

Sebagian partisipan mengungkapkan ada masalah dari keluarga pasien yaitu keluarga pasien yang berganti-ganti berulang di edukasi dan tidak mematuhi peraturan. Seperti diungkapkan partisipan berikut ini:

"Banyak, pasien berganti-ganti, keluarga pasien berganti-ganti, sudah kita edukasi pun sudah tanda tangan , nama nya manusia tetap aja ada yang gak nurut aturan jadi setiap bisa berulang-ulang kita menyampaikan hal yang sama" [ P10, L 311-313]

\section{c. Perilaku buruk petugas kesehatan}

Sebagian partisipan mengungkapkan ada perilaku buruk dari petugas kesehatan yaitu perawat, koas, dokter lupa mencuci tangan. Seperti diungkapkan partisipan berikut ini:

"Kalo itu adanya pasti satu satu, ada yang bandel juga ya kan. Macam-macam lah ada perawat, ada koas, ada dokter cuma gak parah, kalo kita kasih tau ya mereka masih mau lakukan mungkin dia lupa. Cuci tangan, misalnya mau masuk lupa cuci tangan, keluar juga lupa cuci tangan. Ada juga yang lupa memasukkan sampah kemana yang tepat" [ $\mathrm{P} 11, \mathrm{~L}$ 272-278]

\section{Membuat laporan}

\section{a. Laporan surveilans}

Pengawasan juga dilakukan dalam bentuk membuat laporan surveilans. Mayoritas partisipan mengungkapkan membuat laporan surveilans tentang data infeksi maupun data pasien yang terpasang infus, kateter dan sebagainya. Data tersebut dibuat setiap hari dan dilaporkan setiap akhir bulan ke IPCN atau PPI. Hal ini seperti ungkapan partisipan, yaitu:

"Membuat laporan ada setiap bulan, mengumpulkannya setiap hari, dicatat ada bukunya baru di laporkan setiap bulan, berapa yang infeksi. Sekarang sudah masuk ke komputer, sebelumnya di tulis tangan" [P5, L 146-148] 
Beberapa hambatan dalam melaksanakan pengendalian infeksi yaitu dari tim kerja, keluarga pasien dan waktu kerja partisipan. Berikut terlihat dalam sub tema yaitu: 1) Hambatan dari tim kerja, 2) Hambatan dari pasien dan keluarga pasien, 3) Hambatan dari waktu kerja. Masing-masing sub tema akan dijelaskan sebagai berikut :

\section{Hambatan dari tim kerja}

\section{a. Kurang kepatuhan}

Beberapa partisipan mengungkapkan dari tim kerja ada hambatan tapi tidak terlalu parah seperti kurangnya kepatuhan dalam menggunakan APD dan mencuci tangan. Hal ini seperti ungkapan partisipan, yaitu:

"Hambatan itu dari kami tim perawatnya dan kesehatan lain, hambatannya kurangnya kepatuhan untuk menggunakan APD dan melaksanakan cuci tangan" [ P1, L 380-382]

\section{Hambatan dari pasien dan keluarga pasien}

\section{a. Kurang pemahaman}

Mayoritas partisipan mengungkapkan ada hambatan dari pasien dan keluarga yaitu keluarga pasien yang berganti-ganti sehingga harus berulang-ulang di edukasi, dan terkadang ada yang kurang mengerti bahasa Indonesia. Seperti diungkapkan partisipan berikut ini:

"Adalah, nanti sudah kita terangkan sama yang ini rupanya yang lain lagi yang jaga, itulah hambatannya, jadi kurang paham kali lagi semua karena berganti-ganti, jadi ngulang lagi" [ P3, L 215-217]

\section{Hambatan dari waktu kerja}

\section{a. Kurang waktu kerja}

Beberapa partisipan mengungkapkan hambatan dari waktu kerja ada di karenakan adanya tugas yang merangkap-rangkap seperti IPCLN merangkap sebagai ketua tim atau $\mathrm{Cl}$ dan perawat pelaksana. Hal ini seperti ungkapan partisipan, yaitu:

"Banyaklah hambatannya, kek ginilah gak tau lagi yang mana yang mau dikerjakan saking dabel-dabel nya kerjaan, merangkaprangkap semua, laporan tadi pun keteter buatnya" [ P3, L 222-224]

\section{DISKUSI}

\section{Melakukan pengawasan yang ketat}

Berdasarkan hasil penelitian pengawasan pengendalian infeksi dilaksanakan dengan ketat yaitu setiap hari dan setiap saat. Tema ini terdiri dari 5 sub tema, yaitu: 1) Pengawasan terhadap pasien, 2) Pengawasan terhadap petugas kesehatan, 3) Pengawasan terhadap lingkungan, 4) Pengawasan terhadap masalah yang ditemukan, 5) Membuat laporan.

Pengawasan yang dilakukan oleh semua partisipan sudah berjalan dengan baik karena partisipan melakukan pengawasan secara menyeluruh terhadap pasien, melihat pasien yang terpasang infus, terpasang kateter, terpasang CVP, juga melihat tanggal-tanggal pemasangan infus kalau sudah 3 hari wajib diganti, selain itu melihat tanda-tanda infeksi yang mungkin terjadi dan linen yang digunakan pasien juga bersih. Sejalan dengan penelitian Lelonowati, Koeswo, \& Rochmad, (2015) bahwa jika tugas pengawasan dilaksanakan dengan baik akan mengurangi kesalahan menjalankan prosedur kerja surveilans infeksi nosokomial.

Pengawasan terhadap petugas kesehatan yaitu semua partisipan mengungkapkan sudah mengawasi petugas kesehatan dalam melakukan tindakan sesuai SOP seperti mencuci tangan, menggunakan APD, dan menjaga kesterilan alat yang dipakai. Partisipan juga akan menegur dan mengingatkan petugas kesehatan bila ada yang tidak mengikuti aturan seperti lupa mencuci tangan, atau menggunakan APD 
pada tempatnya. Hal ini sesuai dengan hasil penelitian Fauzia, Ahsan, \& Azzuhri (2014) menyatakan bahwa sebagian besar kesadaran perawat akan perlunya hand hygiene sudah baik $(94,36 \%)$ dan hanya sebagian kecil perawat yang belum memiliki kesadaran diri dalam melaksanakan hand hygiene di RST dr. Soepraoen Malang.

Pengawasan terhadap lingkungan yaitu semua partisipan mengungkapkan sudah memperhatikan kebersihan ruangan baik ruangan perawat maupun ruangan pasien, pembuangan sampah pada tempatnya sampah infeksius warna kuning dan sampah non infeksius warna hitam, dan sampah dibuang sebelum penuh atau $2 / 3$. Pembersihan ruangan dilakukan dengan melap meja-meja pasien, tempat tidur, menyapu lantai dan mengepel lantai dengan menggunakan pembersih lantai. Hal ini sesuai Pedoman PPIRS RSUP HAM (2012) bahwa pembersihan lingkungan ruang perawatan diutamakan dengan metode usap seluruh permukaan lingkungan menggunakan bahan desinfektan yang efektif.

Pengawasan terhadap masalah yang ditemukan seperti pengawasan terhadap kejadian infeksi, pengawasan terhadap perilaku buruk dari keluarga pasien, dan pengawasan terhadap perilaku buruk petugas kesehatan. Sebagian partisipan mengungkapkan menemukan kejadian infeksi seperti plebitis, ISK, dekubitus, namun masih jarang untuk setiap ruangan dan jumlah infeksi juga sedikit sekitar 1-3 orang. Hal ini tidak sesuai dengan Lelonowati, Koeswo, \& Rochmad, (2015) bahwa perawat IPCLN banyak yang tidak tahu tentang penentuan kriteria suspek infeksi nosokomial seperti IADP, ISK, Ventilator Associated Pnemonia (VAP), Hospital Associated Pneumonia (HAP), dan lain-lain.

Selain itu hampir semua partisipan mengungkapkan IPCLN sudah melakukan pengawasan dengan membuat laporan surveilans, yaitu mengisi format surveilans tentang data-data infeksi dari pasien dicatat setiap hari dan dilaporkan ke IPCN setiap akhir bulan. Hal ini sesuai dengan target surveilans yaitu ISK terkait kateterisasi, ILO, plebitis IRS, dan dekubitus, VAP \& HAP, IADP dan diare (Direktorat Jenderal Pelayanan Medik Spesialistik, Departemen Kesehatan RI, 2001).

\section{Mendapatkan hambatan dalam melaksanakan pengendalian infeksi}

Hasil penelitian ini menunjukkan adanya hal-hal yang menghambat pelaksanaan pengendalian infeksi. Tema ini terdiri dari 3 sub tema yaitu: 1) Hambatan dari tim kerja, 2) Hambatan dari pasien dan keluarga pasien, 3) Hambatan dari waktu kerja.

Sebagian partisipan mengungkapkan ada hambatan dari tim kerja yaitu kurangnya kepatuhan perawat dan petugas kesehatan lain untuk menggunakan APD dan melaksanakan cuci tangan. Partisipan lain lagi mengungkapkan bahwa koas dan dokter susah diingatkan. Hal ini sesuai penelitian Masloman, Kandou, \& Tilaar (2015) menyatakan beberapa faktor yang mempengaruhi petugas kesehatan menggunakan APD dalam menjamin keselamatannya sebelum bersentuhan dengan pasien dan melakukan tindakan yaitu motivasi, perilaku, kebiasaan maupun ketersediaan APD tersebut.

Hambatan dari pasien dan keluarga pasien mayoritas partisipan mengungkapkan hambatan dikarenakan keluarga pasien yang menjaga selalu berganti-ganti sehingga harus berulang-ulang memberikan pengarahan tentang cuci tangan dan terkadang ada yang kurang mengerti bahasa Indonesia. Hal ini sesuai dengan Green \& Fisk (1986) menyebutkan bahwa salah satu faktor yang 
mempengaruhi perilaku seseorang adalah pengetahuan.

Sebagian partisipan mengalami hambatan dari waktu kerja yaitu kurang waktu kerja seperti yang diungkapkan partisipan bahwa pekerjaan yang merangkap-rangkap, membuat laporan pun tidak sempat. Hal ini dikarenakan peran ganda perawat, dimana perawat tidak hanya sebagai IPCLN tapi merangkap juga sebagai perawat pelaksana, atau sebagai katim dan ada juga sebagai $\mathrm{Cl}$ di ruangan. Hal ini sesuai dengan penelitian Lelonowati, Koeswo, \& Rochmad (2015) bahwa IPCLN mengalami kendala dalam pelaksanaan tugas dan fungsinya dalam pengendalian infeksi karena mempunyai tugas rangkap dan kurangnya pengetahuan pribadi tentang tugas.

\section{SIMPULAN}

Berdasarkan hasil penelitian dan pembahasan dapat disimpulkan pengalaman perawat dalam menerapkan manajemen pengendalian infeksi. Adapun tema terdiri dari: 1) Melakukan pengawasan yang ketat, 2) Mendapatkan hambatan dalam melaksanakan pengendalian infeksi. Berdasarkan hasil penelitian, diberikan beberapa saran terhadap praktik keperawatan dan rumah sakit, pendidikan keperawatan, dan penelitian keperawatan. Seharusnya setiap petugas kesehatan patuh dan tidak perlu lagi diingatkan dalam melaksanakan cuci tangan 6 langkah, 5 momen dan menggunakan APD untuk melindungi dirinya dan pasien dari terjadinya infeksi. Hasil penelitian ini dapat diterapkan ke mahasiswa agar melaksanakan pengendalian infeksi ketika praktek di rumah sakit. Penelitian ini dapat digunakan sebagai data dasar untuk melakukan penelitian kualitatif yang lebih mendalam terhadap tema-tema yang telah diperoleh.

\section{DAFTAR PUSTAKA}

Colaizzi, P. F. (1978). Psychological research as the phenomenologist view it. In Ronald S. Valle \& Mark King (Eds.), Existential-phenomenological alternatives for psychology. New York: Oxford University Press.

Creswell, J. W. (1998). Qualitative inquiry: Choosing among five tradition. Thousand Oaks, CA, US: Sage Publications, Inc.

Direktorat Jenderal Pelayanan Medik Spesialistik, Departemen Kesehatan RI. (2001). Pedoman Pengendalian Infeksi Nosokomial di Rumah Sakit. Jakarta: Departemen Kesehatan RI.

Ernawati, E., Tri R, A., Satra Wiyanto, S. (2014). Penerapan hand hygiene perawat di ruang rawat inap rumah sakit. Jurnal Kedokteran Brawijaya, 28(1):89-94.

Fauzia, N., Ahsan, \& Azzuhri, M. (2015). Pengaruh faktor individu, organisasi dan perilaku terhadap kepatuhan perawat dalam melaksanakan hand hygiene di ruang rawat inap Rumah Sakit Tk. II Dr. Soepraoen Malang. Jurnal Aplikasi Manajemen, 13(4): 566-574.

Green, S. T. \& Fisk P. (1986). Avoiding needle pricks. The Lancet, 327(8489): 1096.

Guba, E. G. \& Lincoln, Y. S. (1994). Competing paradigms in qualitative research. In N. K. Denzin \& Y.S. Lincoln (Eds), Handbook of qualitative research (pp.15-117). Thousand Oaks, CA: Sage.

Huber, D. (2010). Leadership nursing and care management (Seventh edition). Philadelphia: W. B. Saunders Company. Masloman, A. P., Kandou, G. D., \& Tilaar, Ch. R. (2015). Analisis pelaksanaan pencegahan dan pengendalian infeksi di kamar operasi RSUD Dr Sam Ratulangi Tondano. JIKMU, 5(3): 238-249.

RSUD Kota Yogyakarta. (2015). Pedoman pencegahan dan pengendalian infeksi nosokomial RSUD Kota Yogyakarta. 
Yogyakarta: RSUD Kota Yogyakarta.

Scheckler, W. E., Brimhall, D., Buck A. S., Farr, B. M., Friedman, C., Garibaldi R. A., Gross, P. A., ..., Solomon, S. L. (1998). Requirements for infrastructure and essential activities of infection control and epidemiology in hospitals. Am J Infec Control, 26(1): 47-60.

Lelonowati, D., Koeswo, M., Rochmad, K. (2015). Faktor Penyebab Kurangnya Kinerja Surveilans Infeksi Nosokomial di RSUD Dr. Iskak Tulungagung. Jurnal Kedokteran Brawijaya, 28(2): 186-194.

World Health Organization, Regional Office for South-East Asia and Regional Office for Western Pacific. (2004). Practical guidelines for infection control in health care facilities world health organization regional office for western pacific, Manila regional office for south-east Asia. India: World Health Organization.

Yusirwan (2012). Pedoman pencegahan dan pengendalian infeksi nosokomial RSUP HAM. Medan : RSUP HAM. 